\title{
Homoeolog-specific retention and use in allotetraploid Arabidopsis suecica depends on parent of origin and network partners
}

\author{
Peter L Chang ${ }^{1}$, Brian P Dilkes ${ }^{2,3}$, Michelle McMahon ${ }^{4}$, Luca Comai ${ }^{2}$, Sergey V Nuzhdin ${ }^{1 *}$
}

\begin{abstract}
Background: Allotetraploids carry pairs of diverged homoeologs for most genes. With the genome doubled in size, the number of putative interactions is enormous. This poses challenges on how to coordinate the two disparate genomes, and creates opportunities by enhancing the phenotypic variation. New combinations of alleles co-adapt and respond to new environmental pressures. Three stages of the allopolyploidization process - parental species divergence, hybridization, and genome duplication - have been well analyzed. The last stage of evolutionary adjustments remains mysterious.

Results: Homoeolog-specific retention and use were analyzed in Arabidopsis suecica (As), a species derived from $A$. thaliana (At) and A. arenosa (Aa) in a single event 12,000 to 300,000 years ago. We used 405,466 diagnostic features on tiling microarrays to recognize At and Aa contributions to the As genome and transcriptome: 324 genes lacked Aa contributions and 614 genes lacked At contributions within As. In leaf tissues, 3,458 genes preferentially expressed At homoeologs while 4,150 favored Aa homoeologs. These patterns were validated with resequencing. Genes with preferential use of $A a$ homoeologs were enriched for expression functions, consistent with the dominance of Aa transcription. Heterologous networks - mixed from At and Aa transcripts - were underrepresented.

Conclusions: Thousands of deleted and silenced homoeologs in the genome of As were identified. Since heterologous networks may be compromised by interspecies incompatibilities, these networks evolve co-biases, expressing either only Aa or only At homoeologs. This progressive change towards predominantly pure parental networks might contribute to phenotypic variability and plasticity, and enable the species to exploit a larger range of environments.
\end{abstract}

\section{Background}

An allotetraploid is formed when diploids from two different species, which may have diverged for millions of years, hybridize. The resulting plant, if viable, might have a competitive edge, such as broader ecological tolerance compared to its parents [1-3]. The evolutionary importance of polyploidy, of which allotetraploidy is a common form, is reflected in its prevalence in flowering plants [4]: ancient polyploidy is apparent in all plant genomes sequenced to date and is estimated to have been involved in $15 \%$ of all plant speciation events [5].

\footnotetext{
* Correspondence: snuzhdin@usc.edu

'Molecular and Computational Biology, University of Southern California,

1050 Childs Way, RRI 201, Los Angeles, CA 90089-2910, USA

Full list of author information is available at the end of the article
}

Furthermore, most cultivated crops have undergone polyploidization during their ancestry $[5,6]$. Why are polyploids so evolutionarily, ecologically, and agriculturally successful? To answer this question, one has to consider the evolutionary and genetic processes acting at different stages of polyploidization.

Allopolyploidization can be characterized by four distinct stages. Stage 1 is the divergence between parental species, with both species adapting to specific environments and adopting their own mating strategies and reproductive schedules. Directional selection can contribute to the fixation of species-specific beneficial mutations in coding and regulatory regions $[7,8]$, while slightly deleterious mutations are introduced due to drift. In stages 2 and 3 , the diverged species hybridize and increase ploidy,
Ciomed Central

() 2010 Chang et al.; licensee BioMed Central Ltd. This is an open access article distributed under the terms of the Creative Commons Attribution License (http://creativecommons.org/licenses/by/2.0), which permits unrestricted use, distribution, and reproduction in any medium, provided the original work is properly cited. 
with the two events sometimes reversed in order [9]. This change in ploidy enables the correct pairing at meiosis. Hybridization frequently results in phenotypic instability, widespread genomic rearrangements, epigenetic silencing, and unusual splicing [3,10-25]. Newly created polyploids often experience rapid intragenomic adjustments. Stages 2 and 3 are well-studied with artificial polyploids constructed in the laboratory $[10,12-17,19,22-24]$ or spontaneously arising in nature $[14,26]$.

Stage 4 is the long term evolution of homoeologous genes (that is, homologous genes from two parents joined into one polyploid genome and stably inherited). This stage occurs much slower on the evolutionary time-scale and has received considerably less attention, perhaps due to several technical limitations. Sequence analyses have historically required extensive cloning and bioinformatics. Microarrays have had to be specifically designed to distinguish between homoeologs and orthologs. Interesting patterns have been reported, but typically for a few genes [14,27-29]. Notably, the retention and expression of homoeologs is frequently biased towards one parental species. These patterns were reported on a large scale for approximately 1,400 out of 42,000 genes in cotton [30-32], and for dozens in Tragopogon [33]. Recent studies have also discovered abundant genetic variation among independently originated or evolved accessions of Tragopogon [34-36]. What molecular evolutionary processes account for this variation among accessions? How does intraspecific variation in polyploid genomes contribute to phenotypic variation? These questions remain wide open.

Here, we focus on Arabidopsis suecica (As), a highly selfing species [37] found mainly in central Sweden and southern Finland [38]. As originated 12,000 to 300,000 years ago (KYA) from a cross between a largely homozygous ovule-parent Arabidopsis thaliana $(A t, 2 \mathrm{n} 10)$ and a pollen-parent Arabidopsis arenosa $(A a, 2 \mathrm{n}=16)$ [39-41]. A single origin of As $(2 \mathrm{n}=26)$ has been established with mitochondrial, chloroplast, and nuclear DNA [39-41]. As originated south of the ice cover and spread north when the ice retreated 10,000 years ago [39]. At is an annual, weedy, and mostly autogamous species native to Europe and central Asia but naturalized worldwide [42]. It has undergone at least two rounds of ancient polyploidization [26] and is annotated with 39 thousand genes. $A a$ is a self-incompatible member of the Arabidopsis genus, carrying the highest level of genetic diversity among the species group [43]. At and $A a$ diverged approximately 5 million years ago [44].

One can generate an artificial $\mathrm{F}_{1}$ allotetraploid $\left(F_{1} A s\right)$ in the lab by performing a cross between a tetraploid $A t$ ovule-parent and a tetraploid $A a$ pollen donor. The resulting primary species hybrid contains two genomes from $A t$ and two from $A a$. We can use this as an estimate, as the exact haplotypes that contributed to the initial hybridization event are not available, of the genomic composition and homoeolog-specific expression at the time of allopolyploid speciation $[24,45,46]$. Taking these patterns as reflective of the As ancestral state, we observed how evolution has shaped the $A s$ genome. As $A t$ is a selfer and $A a$ an outcrosser, $A t$-originated homoeologs might have possessed more deleterious mutations due to Hill-Robertson interference [47]. Are $A a$-originated homoeologs more commonly retained? At and Aa evolved orthologous networks in which genes were finely tuned to coordinate, separately within each species. Interference of $A t$ and $A a$ homoeologs may cause mis-regulation within mixed $A s$ networks. This is akin to Dobzhansky-Muller incompatibilities [48]. Do heterologous networks evolve to restore their original orthologous-like compositions? Here, we address these and other questions.

\section{Results}

For every gene in $A s$, we set to determine whether both $A t$ and $A a$ homoeologs are present in the genome and whether they are expressed evenly or in homoeolog-specific fashion [49]. With the genome-wide Arabidopsis tiling microarray, we scanned the genomes of $A t, A a, A s$, and $F_{1} A s$. We analyzed the transcriptome of $A s$ with tiling arrays and validated results with Illumina resequencing. We assembled a statistical pipeline to identify $A t$ and $A a$ homoeolog-originated signals, and to estimate their contribution to the As populations of DNA and RNA.

\section{Comparison of probe hybridization between parental species, and between $A s$ and $F_{1} A s$}

The Arabidopsis array features 3.2 million 25-base-long probes tiled throughout the complete genome at a 35base distance. As these features are homologous to the $A t$ reference, they should, on average, exhibit a lower hybridization with $A a$ DNA. Probe intensities confirm this expectation. Two typical examples are shown for chromosomes 3 and 4 (Figures 1 and 2; see Additional files 1, 2, 3,4, 5 and 6 for other examples). $F_{1} A s$ signals are a sharp intermediate between $A t$ and $A a$. As shows remarkable correspondence with $F_{1} A s$, with the exception of several extended regions. We hypothesize that these regions correspond to historic losses of homoeologous chromosomal regions in As.

We mapped features onto the genes and compared intensities between $A s$ and $F_{1} A s ; 6,790$ genes exhibited differential hybridization (Wilcoxon ranked sum test, false discovery rate $(F D R)<0.05)$. To identify large putative alterations, we scanned for clusters containing at least 30 genes with a strong unidirectional bias (at least 27 with the same bias, significant for at least 9 genes). We identified 39 clusters, encompassing 1,643 genes (Table 1). Some clusters were due to differential abundance of 

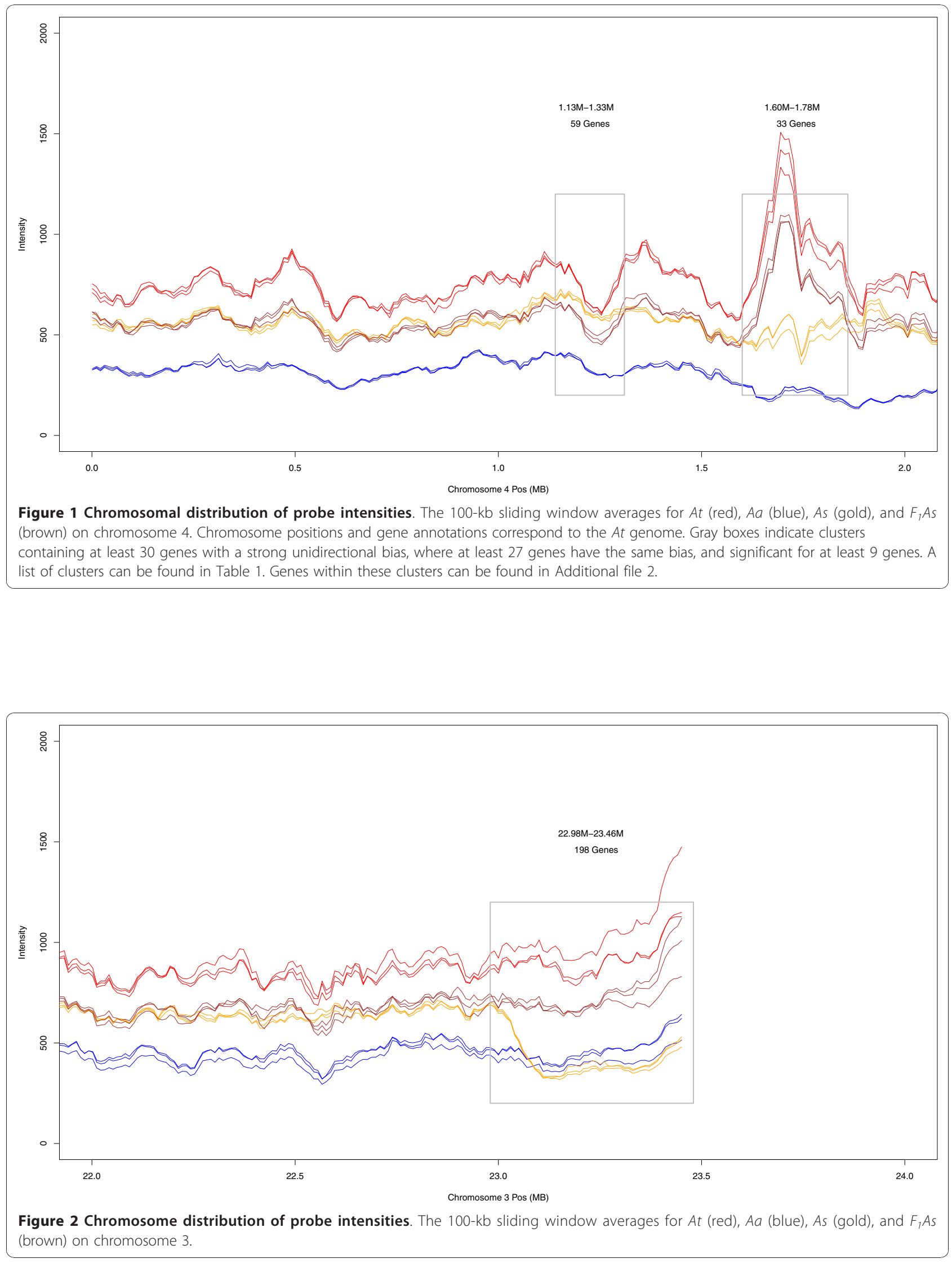
Table 1 Regions of putative alterations in Arabidopsis suecica

\begin{tabular}{|c|c|c|c|c|c|c|}
\hline Chromosome & Region & $\begin{array}{l}\text { Number of } \\
\text { genes }\end{array}$ & $\begin{array}{c}\text { Percent with differential } \\
\text { hybridization }\end{array}$ & $\begin{array}{l}\text { Percent } \\
\text { TEs }\end{array}$ & $\begin{array}{l}\text { Number of } \\
\text { probes }\end{array}$ & $\begin{array}{c}\text { Higher } \\
\text { hybridization in? }\end{array}$ \\
\hline \multirow[t]{7}{*}{ AT1 } & $0.29 \mathrm{M}-0.39 \mathrm{M}$ & 38 & 44.7 & 0 & 2,537 & $F_{1}$ As \\
\hline & $0.82 \mathrm{M}-0.91 \mathrm{M}$ & 32 & 28.1 & 3.1 & 2,266 & $F_{1}$ As \\
\hline & $3.16 \mathrm{M}-3.29 \mathrm{M}$ & 43 & 37.2 & 0 & 3,175 & As \\
\hline & $8.40 \mathrm{M}-8.49 \mathrm{M}$ & 37 & 29.7 & 2.7 & 1,991 & $F_{1}$ As \\
\hline & $13.66 \mathrm{M}-13.86 \mathrm{M}$ & 43 & 58.1 & 51.2 & 3,547 & $F_{1}$ As \\
\hline & $14.00 \mathrm{M}-14.39 \mathrm{M}$ & 70 & 42.9 & 51.4 & 5,998 & $F_{\uparrow}$ As \\
\hline & $29.97 \mathrm{M}-30.07 \mathrm{M}$ & 40 & 32.5 & 0 & 2,536 & $F_{1}$ As \\
\hline \multirow[t]{6}{*}{ AT2 } & $1.96 \mathrm{M}-2.03 \mathrm{M}$ & 34 & 32.4 & 8.8 & 1,377 & As \\
\hline & $4.57 \mathrm{M}-4.69 \mathrm{M}$ & 30 & 30.0 & 36.7 & 2,302 & $F_{1}$ As \\
\hline & $6.50 \mathrm{M}-6.67 \mathrm{M}$ & 43 & 27.9 & 16.3 & 3,214 & As \\
\hline & $10.88 \mathrm{M}-11.01 \mathrm{M}$ & 38 & 26.3 & 0 & 3,182 & As \\
\hline & $14.74 \mathrm{M}-14.84 \mathrm{M}$ & 37 & 27.0 & 0 & 2,440 & $F_{1}$ As \\
\hline & $19.60 \mathrm{M}-19.68 \mathrm{M}$ & 36 & 38.9 & 0 & 2,065 & $F_{1}$ As \\
\hline \multirow[t]{12}{*}{ AT3 } & $0.30 \mathrm{M}-0.36 \mathrm{M}$ & 33 & 42.4 & 0 & 1,568 & $F_{1}$ As \\
\hline & $5.58 \mathrm{M}-5.68 \mathrm{M}$ & 32 & 46.9 & 0 & 2,299 & As \\
\hline & $7.30 \mathrm{M}-7.38 \mathrm{M}$ & 31 & 32.3 & 16.1 & 1,822 & $F_{\uparrow}$ As \\
\hline & $12.44 \mathrm{M}-12.61 \mathrm{M}$ & 36 & 27.8 & 61.1 & 3,055 & $F_{1}$ As \\
\hline & $13.36 \mathrm{M}-13.50 \mathrm{M}$ & 34 & 55.9 & 50.0 & 2,431 & As \\
\hline & $14.55 \mathrm{M}-14.70 \mathrm{M}$ & 39 & 38.5 & 33.3 & 2,904 & As \\
\hline & $20.25 \mathrm{M}-20.34 \mathrm{M}$ & 31 & 32.3 & 3.2 & 2,165 & $F_{1}$ As \\
\hline & $20.93 \mathrm{M}-21.00 \mathrm{M}$ & 30 & 30.0 & 0 & 1,881 & $F_{1}$ As \\
\hline & $21.30 \mathrm{M}-21.43 \mathrm{M}$ & 44 & 34.1 & 2.3 & 3,227 & $F_{1}$ As \\
\hline & $21.60 \mathrm{M}-21.73 \mathrm{M}$ & 45 & 44.4 & 0 & 3,217 & $F_{1}$ As \\
\hline & $22.11 \mathrm{M}-22.22 \mathrm{M}$ & 37 & 29.7 & 0 & 2,520 & $F_{1}$ As \\
\hline & $22.98 \mathrm{M}-23.46 \mathrm{M}$ & 198 & 79.8 & 2.0 & 12,309 & $F_{1}$ As \\
\hline \multirow[t]{6}{*}{ AT4 } & $1.13 \mathrm{M}-1.33 \mathrm{M}$ & 59 & 28.8 & 1.7 & 4,967 & As \\
\hline & $1.60 \mathrm{M}-1.78 \mathrm{M}$ & 33 & 57.6 & 39.4 & 2,762 & $F_{1}$ As \\
\hline & $7.59 \mathrm{M}-7.68 \mathrm{M}$ & 34 & 29.4 & 2.9 & 2,052 & As \\
\hline & $7.67 \mathrm{M}-7.82 \mathrm{M}$ & 47 & 23.4 & 21.3 & 3,232 & As \\
\hline & $16.89 \mathrm{M}-16.96 \mathrm{M}$ & 32 & 34.4 & 0 & 1,797 & As \\
\hline & $17.86 \mathrm{M}-17.95 \mathrm{M}$ & 39 & 38.5 & 0 & 2,000 & $F_{1}$ As \\
\hline \multirow[t]{7}{*}{ AT5 } & $9.92 \mathrm{M}-10.11 \mathrm{M}$ & 44 & 43.2 & 22.7 & 4,269 & As \\
\hline & $11.06 \mathrm{M}-11.27 \mathrm{M}$ & 42 & 45.2 & 59.5 & 2,948 & $F_{1}$ As \\
\hline & $13.76 \mathrm{M}-13.89 \mathrm{M}$ & 38 & 36.8 & 18.4 & 2,785 & As \\
\hline & $18.49 \mathrm{M}-18.61 \mathrm{M}$ & 33 & 30.3 & 0 & 2,882 & As \\
\hline & $20.53 \mathrm{M}-20.70 \mathrm{M}$ & 34 & 29.4 & 2.9 & 2,621 & As \\
\hline & $23.48 \mathrm{M}-23.56 \mathrm{M}$ & 33 & 30.3 & 0 & 1,991 & $F_{1}$ As \\
\hline & $26.41 \mathrm{M}-6.47 \mathrm{M}$ & 34 & 29.4 & 0 & 1,453 & $F_{1} A s$ \\
\hline ATM & $0.02 \mathrm{M}-.24 \mathrm{M}$ & 30 & 50.0 & 0 & 1,447 & $F_{1}$ As \\
\hline
\end{tabular}

As, Arabidopsis suecica; F1As, F1 artificial allotetraploid.

transposable-element-like sequences. Chr1 13.66 M, Chr1 14.00 M, Chr3 12.44 M, Chr3 13.36 M, and Chr5 11.06 M mainly consisted of copia-like, gypsy-like, or CACTA-like retrotransposons. Other regions - for instance, on Chr1 $0.29 \mathrm{M}$, Chr3 0.30 M, Chr3 $5.58 \mathrm{M}$, Chr3 $21.60 \mathrm{M}$, and Chr3 $22.98 \mathrm{M}$ - appeared free from this problem (Additional file 2 includes detailed information). Interestingly, the region $1.60 \mathrm{M}-1.78 \mathrm{M}$ on chromosome 4 (Figure 1) is coincident with the heterochromatic knob known to be hypervariable in $A t$ [50]. The $22.98 \mathrm{M}-23.46 \mathrm{M}$ region of chromosome 3 (Figure 2) looked like an $A t$-homoeolog deletion. These results show that tiling arrays can be a useful tool for detecting copy number variation [51] and large-scale alterations in the $A s$ genome. As these analyses are based on non-normalized signals (between species), they are likely error-prone for individual genes. 


\section{Homoeolog-specific retention}

To analyze the homoeolog-specific retention and expression of individual genes, we focused on 1,393,557 probes mapping to coding regions using Bowtie [52]. Since $A a$ and $A t$ sequences differ at 1 out of 20 bases, some 25base oligonucleotides designed for $A t$ are a perfect match for $A a$ sequences. Whenever orthologous $A a$ sequences mis-match to the $A t$ chip, this hybridization is weakened (hereafter termed 'diagnostic features' (DFs)). Separately for every gene, we identified a scaling factor based on probes with similar signatures of hybridization to normalize intensities between species. We then identified homoeolog-specific DFs and only retained those $(405,466)$ robust over replicates (Figure 3 ). We could only follow 24,344 genes as the fastest- evolving genes have too many DFs for normalization (Additional file 3).

We tested for deviations from an equal representation of the two homoeologs in the As genome [12,16,53]. As a reference point, we used the $F_{1} A s$ DNA in which homoeologs are present at equal doses (Figure 1). For each gene within the regions of putative alterations, we tested for changes in $\alpha$ between $A s$ and $F_{1} A s$, where $\alpha$ represents the relative contribution of $A a$ DF hybridization strengths in a hybrid genome. There was an upward shift in $\alpha$ in $A s$ compared to $F_{1} A s$ (one-sided paired $t$ test, $P<2 \mathrm{e}-17$ ), suggesting a preferential retention of homoeologs derived from the $A a$ parent (Figure 4). Supporting this, more genes were called $A a$-like (614) than At-like (324). This bias is significant, although moderate
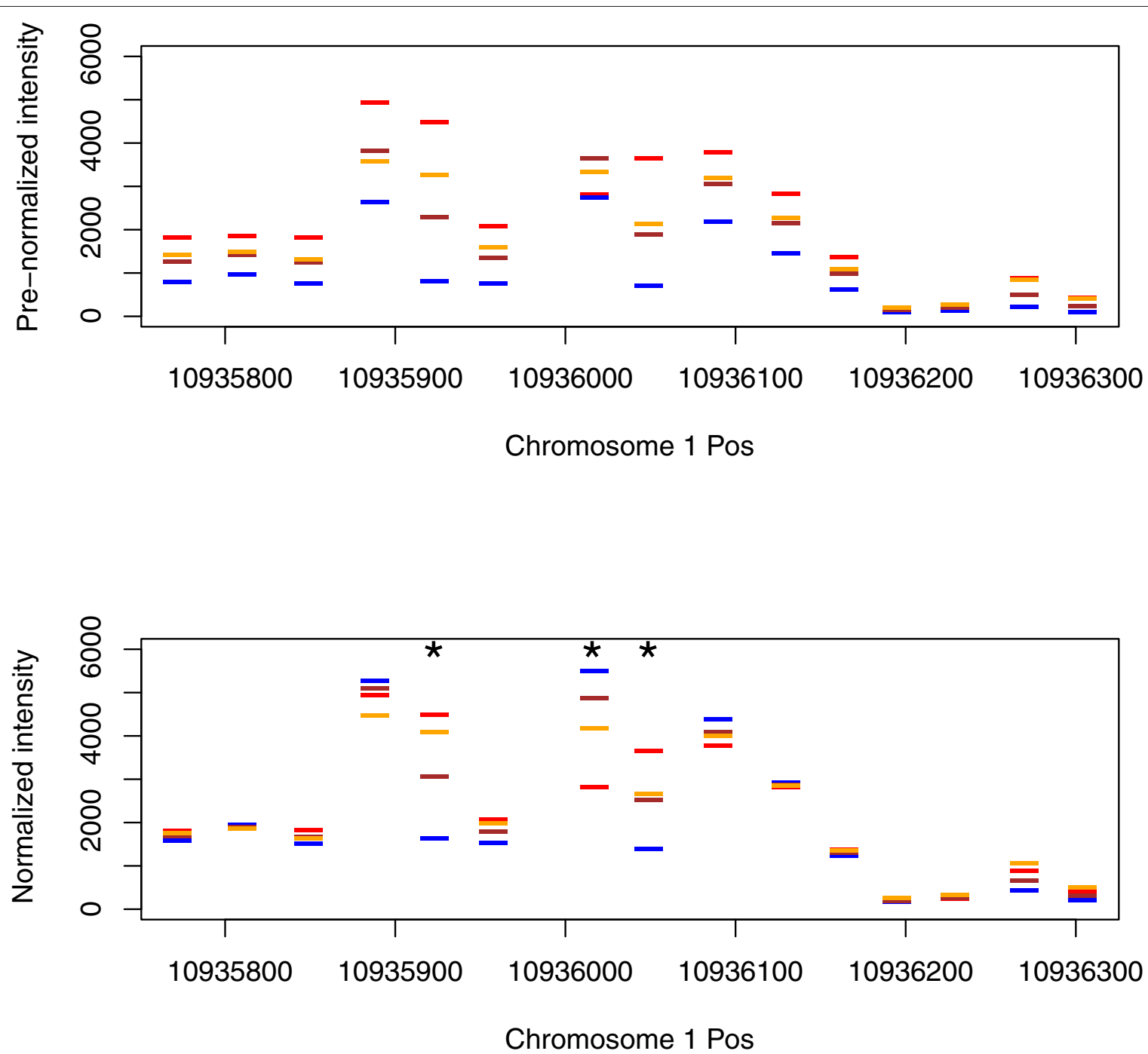

Figure 3 Probe intensities before and after normalization. Probe intensities for every gene were normalized to identical levels in all arrays. A t-test between At (red) and Aa (blue) replicates identified diagnostic features (shown with asterisks) that were used to identify homoeologspecific hybridization. $F_{1}$ As (brown) is shown as a null reference for which to compare As (gold). 


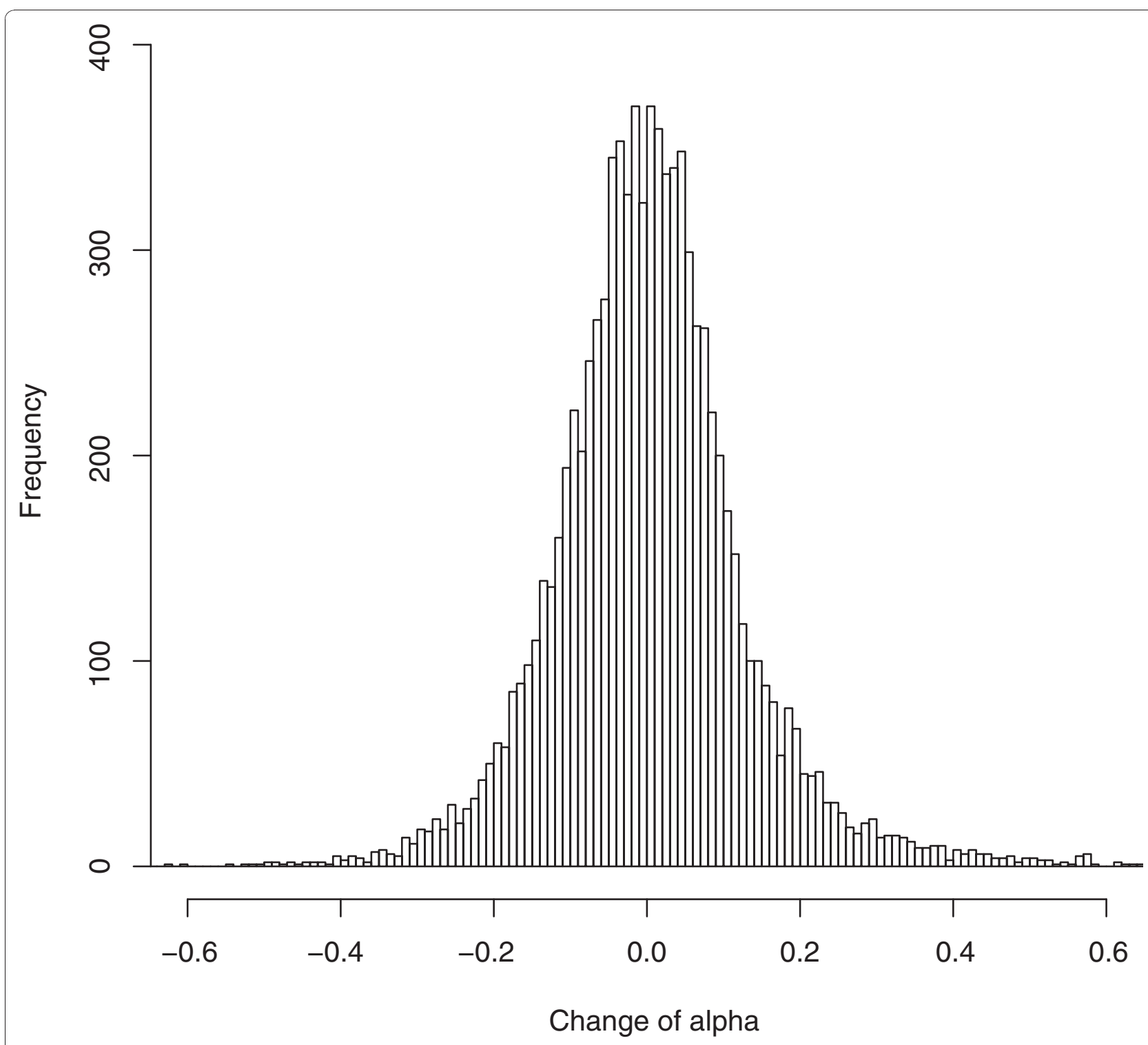

Figure 4 Histogram distribution of homoeolog bias $\Delta \boldsymbol{\alpha}$. $\Delta \boldsymbol{\alpha}$ is shown for the genome of $A s$, using $F_{1} A s$ as a null reference. Distribution is nearly symmetrical and centered at 0.004 .

compared to earlier studies [30-32,34-36]. This might reflect a limited power of microarrays. For instance, we analyzed 30 genes encoded by the mitochondria organelle known to be $A t$-derived. Only one plastid-encoded gene had enough DFs to be unambiguously classified, and was biased towards maternal $A t$, as expected.

\section{Use of $A t$ and $A a$ homoeologs in As transcriptome}

To identify homoeologous transcripts in As, we extracted RNA from leaf tissues and processed microarrays with the SNP-detection protocols similar to above. More than $49 \%$ of genes were called expressed, and 7,608 exhibited homoeolog-specific expression, with 3,458 and 4,150 exhibiting $A t$-enriched and $A a$-enriched
DFs, respectively. Overall, we conclude that, over the 12,000 to 300,000 years, As has accumulated more deletions of $A t$-originated homoeologs and uses the remaining $A t$-originated homoeologs somewhat less (Table 2). Genes physically clustered together might co-express and co-evolve in transcript levels, as previously observed

Table 2 Homoeolog-specific retention and use in Arabidopsis suecica

\begin{tabular}{lcc}
\hline Classification & As genome & As transcriptome \\
\hline At-like & 324 & 3,458 \\
Aa-like & 614 & 4,150 \\
\hline
\end{tabular}

Aa, Arabidopsis arenosa; As, Arabidopsis suecica; At, Arabidopsis thaliana. 
in flies [54]. To test whether biases in homoeolog-specific expression were concordant between nearby genes, we calculated running averages of $\Delta \alpha$ along chromosomes (Figure 5), and found regions with clusters of Atenriched and $A a$-enriched transcription.
To validate the tiling array-based procedures above, we prepared Illumina libraries and performed RNAsequencing of the As transcriptome. The $A a$ genome is not yet assembled, but we identified $52 A a$ genes from GenBank and acquired an additional 50 genes from the

Chromosome 1

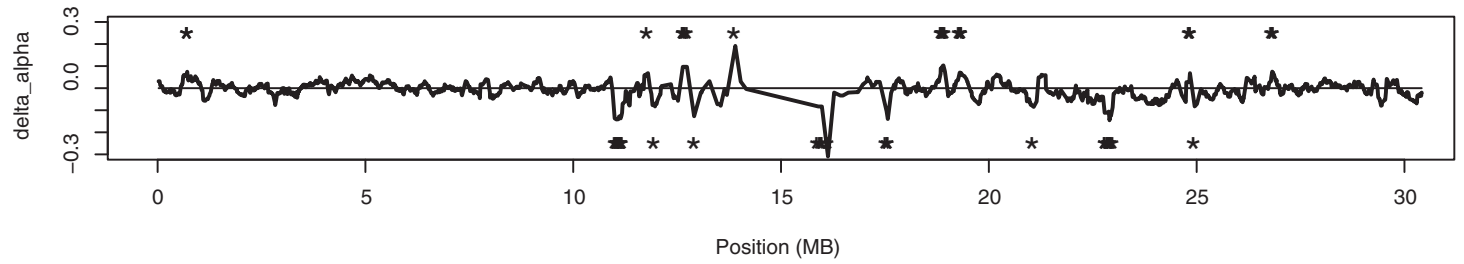

Chromosome 2

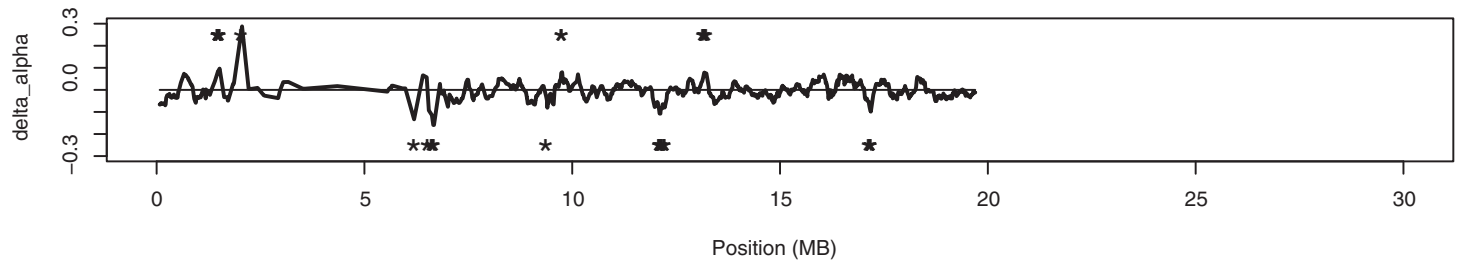

Chromosome 3

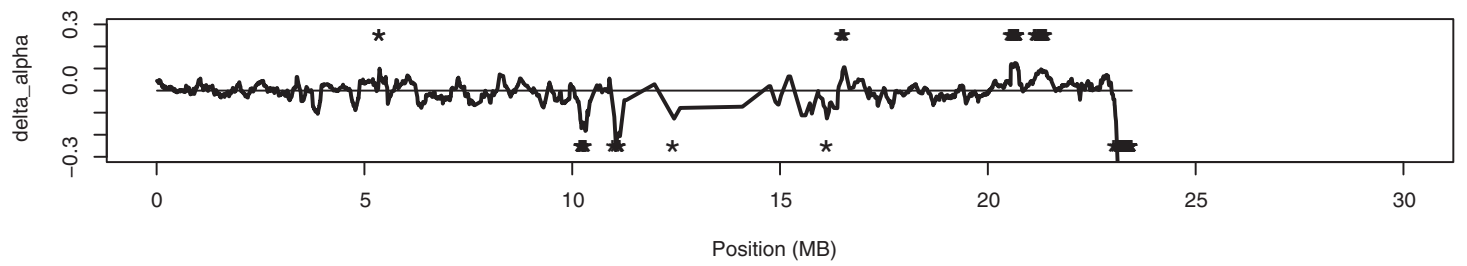

Chromosome 4

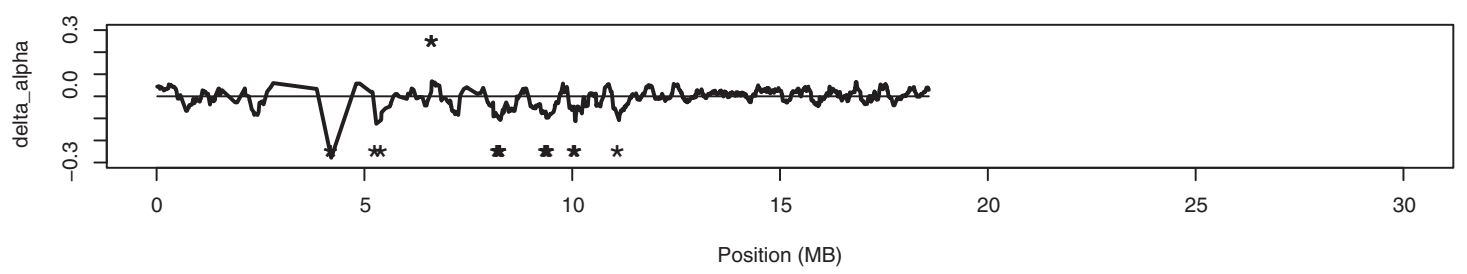

Chromosome 5

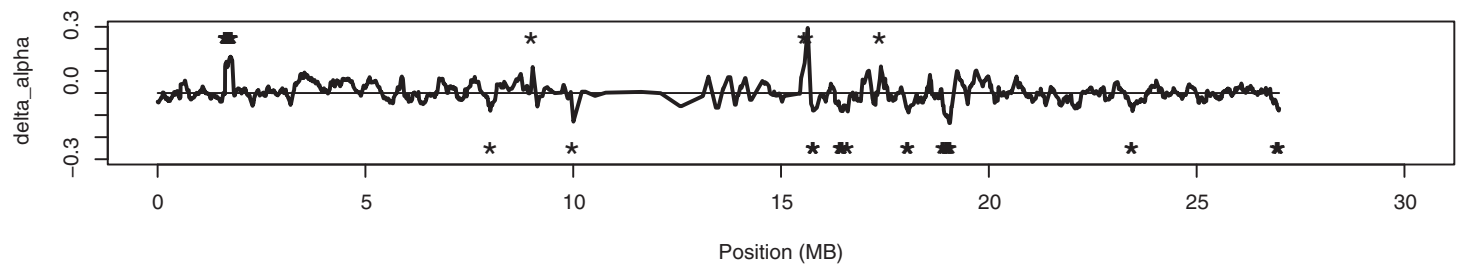

Figure $\mathbf{5}$ Chromosomal distribution of clusters of biased homoeolog transcripts. Lines above the center indicate clusters of At-like genes, and those below indicate of Aa-like genes. Asterisks depict significance using a genome-wide permutation test. Presence of another asterisk indicates a nearby region that is also clustered with At- or Aa-enriched transcription. 
UC Genome Center. We identified the orthologous At genes for these $A a$ genes and mapped the Illumina reads to both homologs. Nine genes did not contain any reads that were mapped to either homolog. For 14 genes, reads only mapped to either the $A a$ or the $A t$ reference. For the remaining genes, reads were aligned to both homologs and clustered as either derived from At or Aa (Figure 6). We consider the number of uniquely mapped reads as a measure of homoeolog-specific expression. A strong correlation in Aa:At expression ratio between tiling arrays and the RNA-seq $\left(R^{2}=\right.$ 0.646, $P<5 \mathrm{e}-07$ ) proves that both approaches work. This concordance is very satisfactory (Figure 7 ) given that RNA samples were extracted from independently grown plants, and that microarray estimates are frequently noisy.

\section{Network analyses of homoeolog-specific genes}

The summary of the Gene Ontology analysis of genes exhibiting homoeolog-specific retention and expression is shown in Tables 3 and 4 . The categories 'cell communication' and 'signal transduction' were underrepresented, while 'DNA repair' and 'response to DNA damage stimulus' were overrepresented. Aa-enriched transcripts were overrepresented in the 'gene expression' category, including subprocesses involved in transcription, translation, RNA processing and gene silencing by miRNA.

Lastly, we considered homoeolog-specific expression in the context of $A t$ transcriptional networks [55]. Of the 7,608 genes, connectedness estimates were available for 6,941 gene pairs. We tested whether bins of higher-connected gene pairs exhibited higher concordance of homoeolog-specific expression (Figure 8). The fraction of concordant pairs was approximately 0.4 in low-connectedness bins, but increased to 0.8 for the high-connected gene pairs $\left(\mathrm{R}^{2}=0.47, P<0.0001\right)$. We also partitioned networks with homoeolog-specific expressions of at least two genes as co-biased for $A a$ (325), co-biased for $A t$ (219), or with mixed biases (302) (Table 5). The latter 'mixed' group was significantly underrepresented in comparison with random expectation $\left(\chi^{2}\right.$ test, $\left.P<6 \mathrm{e}-08\right)$.

\section{Discussion}

In allopolyploid speciation, two genomes that have experienced long independent evolution are combined. Their genomes were shaped in different ways in response to the extrinsic environmental and intrinsic lifestyle pressures. We focused on $A s$, a species that evolved 12 to $300 \mathrm{KYA}$ from a single hybrid individual formed from an ovule of $A t$ and a pollen of $A a$. Orthologous genes of $A t$ and $A a$ have average sequence divergence of 5\% [43], exhibit differences in tissue-specific expression $[10,24]$, and are located on five versus eight chromosomes. The allotetraploid hybrid initially had low fertility, if one can conclude this from the performance of artificial hybrids in the lab. This fertility can be restored through the complex interplay of genetic and epigenetic processes [22]. Several groups have been fascinated with this rapid but complex process [10,22,24, $45,46,53,56-59]$. We focus on the subsequent longerterm molecular evolution, by comparing an evolved natural $A s$ with an 'unevolved' $F_{1} A s$ hybrid.

\section{The summary of $F_{1}$ As unevolved patterns}

$F_{1} A s$ and its following generations are a model for whole-genome rearrangements and gene expression. Approximately one of ten cDNA amplified fragment length polymorphism (AFLP) bands displayed patterns that were non-additive between $F_{1} A s$ and its parental species [16]. One percent of bands were not detected in the parental species altogether [24]. For AFLP fragments observed in the parents, homoeolog silencing was nearly symmetrical: $4 \%$ of $A t$ versus 5\% of $A a$. These patterns varied among tissues in a seemingly stochastic way. There was also some variation among accessions. In addition to AFLPs, Wang et al. [53] used spotted 70mer oligonucleotide arrays to compare gene expression between $A t, A a$, and $F_{1} A s$. More than $15 \%$ of transcripts

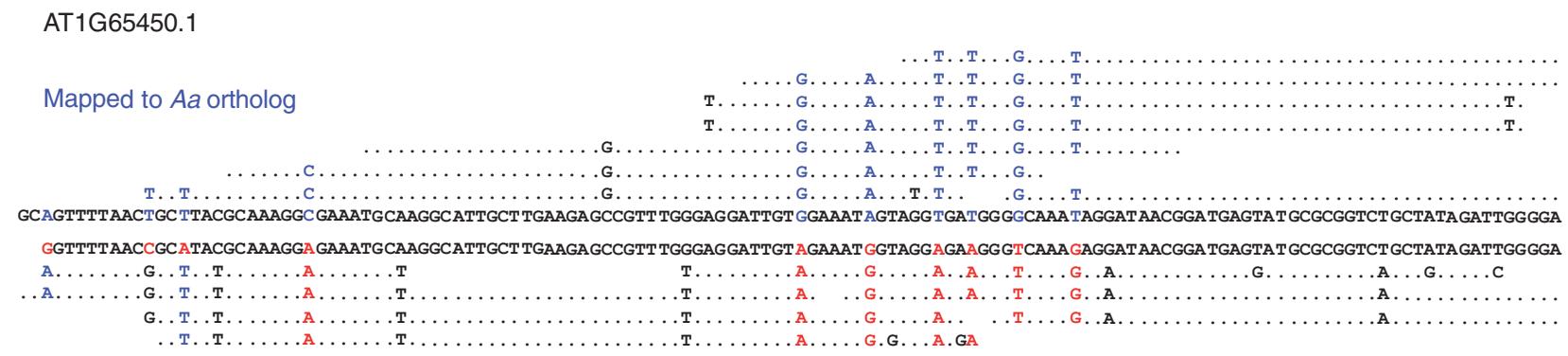

Mapped to At ortholog

Figure 6 Sequenced read alignments to $A t$ and $A a$ orthologs. Orthologous At and Aa sequences shown at center contain diagnostic SNPs in red and blue, respectively, that can be used to align and cluster Illumina reads. 


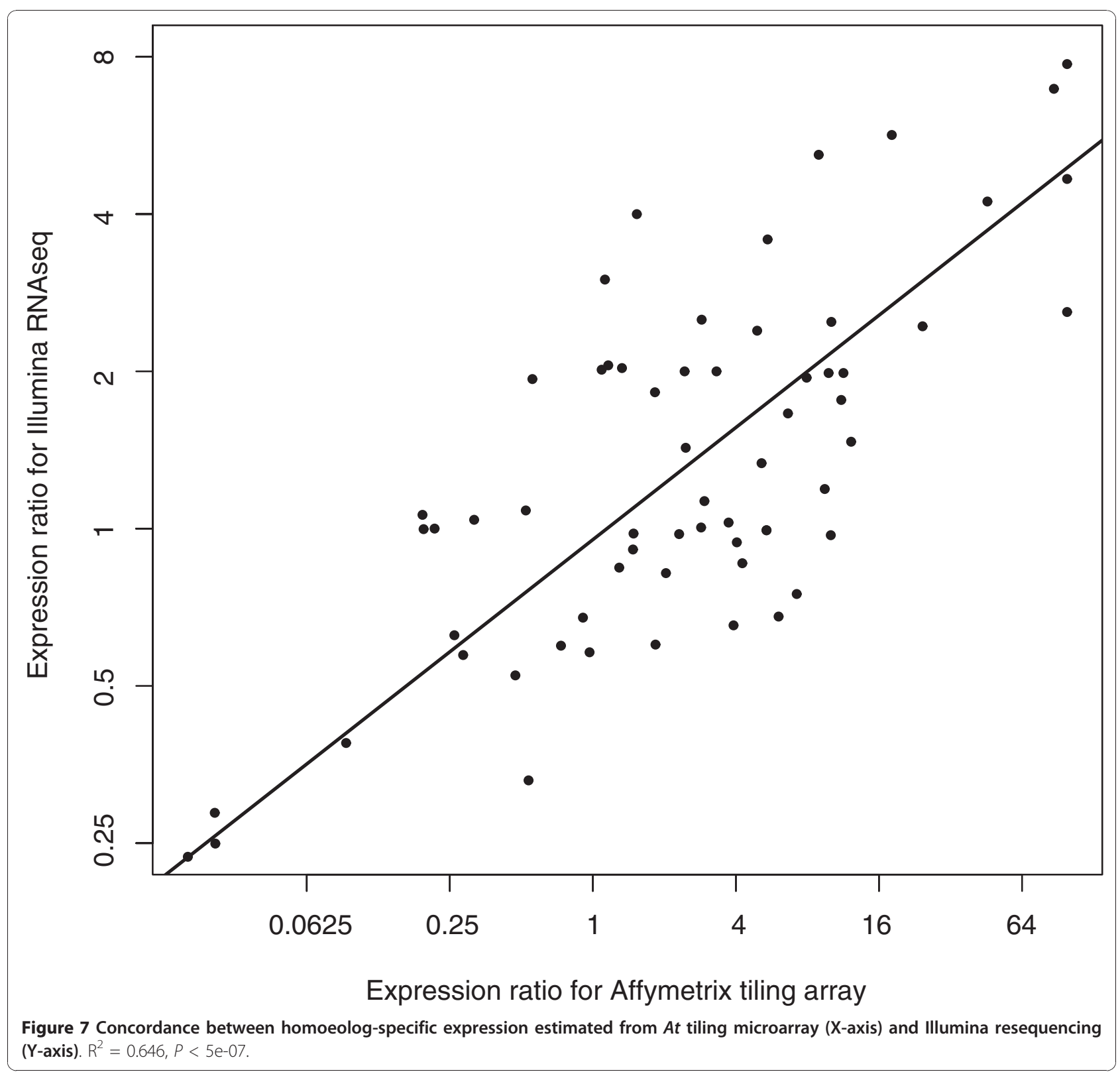

had different levels between parental species. In $F_{1} A s$, $5 \%$ of genes deviated in expression level from the additive mid-parent expectation, with the majority being repressed. Interestingly, $94 \%$ of these genes were more strongly expressed in the At parent, with their levels of expression in $F_{1} A s$ resembling $A a$ [56,57]. In conclusion, the levels of gene expression in $F_{1} A s$ more frequently resemble those in $A a$, although homoeologs seem to have been used symmetrically and sometimes randomly. Aa-specific phenotypes, such as flower morphology, plant stature and long lifespan, are dominant in $F_{1} A s$ (likewise, Arabidopsis lyrata phenotypes are dominant in thaliana-lyrata hybrids [56,59]). These results were confirmed and further detailed in very recent investigations $[24,45,46]$.

\section{Evolved As patterns}

We found that in $A s, A a$ homoeologs are more frequently retained and more actively transcribed than their $A t$ counterparts. We hypothesize that these $A a$ favoring biases are not random, but rather represent a signature of an evolutionary process. To explain these patterns, we propose a concept of 'homoeolog competition.' Genes are subject to detrimental mutations at approximately constant rates [47]. Purifying selection removes these mutations with varying efficiencies 
Table 3 Gene Ontology annotation for homoeolog-biased genes in the Arabidopsis suecica genome, overrepresented unless stated

\begin{tabular}{|c|c|c|}
\hline Classification & Biological process & $\begin{array}{l}P \text { - } \\
\text { value }\end{array}$ \\
\hline \multirow[t]{12}{*}{ At-like } & Sulfur amino acid metabolic process & 0.00078 \\
\hline & Response to fungus & 0.0054 \\
\hline & Heat acclimation & 0.0054 \\
\hline & Aspartate family amino acid metabolic process & 0.012 \\
\hline & mRNA metabolic process & 0.012 \\
\hline & Riboflavin biosynthetic process & 0.013 \\
\hline & Membrane lipid metabolic process & 0.013 \\
\hline & Cellular sodium ion homeostasis & 0.013 \\
\hline & Cellular calcium ion homeostasis & 0.021 \\
\hline & Aspartate family amino acid metabolic process & 0.024 \\
\hline & $\begin{array}{l}\text { Purine ribonucleoside monophosphate } \\
\text { metabolic process }\end{array}$ & 0.035 \\
\hline & Cellular potassium ion homeostasis & 0.036 \\
\hline \multirow[t]{9}{*}{ Aa-like } & Protein amino acid glycosylation & 0.021 \\
\hline & Defense response, underrepresented & 0.029 \\
\hline & DNA repair & 0.024 \\
\hline & Response to DNA damage stimulus & 0.024 \\
\hline & RNA metabolic process & 0.028 \\
\hline & Cell communication, underrepresented & 0.031 \\
\hline & Signal transduction, underrepresented & 0.033 \\
\hline & Hormone transport & 0.044 \\
\hline & Microtubule cytoskeleton organization & 0.044 \\
\hline
\end{tabular}

depending on the gene redundancy, dominance, and other characteristics $[6,21,60,61]$. As some $F_{1} A s$ homoeologs are functionally redundant, they should be progressively lost to mutations and deletions. From the initial pool of homoeologs, natural selection would preferentially maintain those with a higher contribution to fitness. In this sense, homoeologs 'compete'. Despite stoichiometric constraints to maintain stable ratios of dosage among genes [62], there is a well-documented shrinkage of polyploid genomes over time $[6,9,12,15,18,21,25,26]$, as few genes are haploinsufficient [60].

Why would $A t$-originated homoeologs be less valuable? Our first hypothesis is inspired by Hill and Robertson [60]. Selfing organisms, such as $A t$, are less capable of purging mildly deleterious mutations. This is because of severely reduced recombination in comparison to outcrossers, such as $A a[61,63,64]$. This may seem paradoxical, as $A t$ maintains much less variation than $A a$ [43], which one might interpret as mutations in $A a$. When selfing evolves, segregating mutations are quickly purged, as they exhibit their deleterious nature in autozygous individuals. In the short term, selfers are in fact better off [61]. With time, however, Mullers' ratchet kicks in one slightly deleterious mutation after another, resulting in low standing variation but inferior functionality [47]. Selfing is typical of terminal branches on
Table 4 Gene Ontology annotations for homoeologbiased use (expression) in Arabidopsis suecica transcriptome, overrepresented unless stated

\begin{tabular}{lll}
\hline Classification & Biological process & P-value \\
\hline At-like & One-carbon metabolic process & $6.1 \mathrm{e}-05$ \\
& Intracellular protein transport & 0.00012 \\
Macromolecule localization & 0.00012 \\
Microtubule-based movement & 0.00045 \\
Cytoskeleton-dependent intracellular transport & 0.00045 \\
Protein complex assembly & 0.0030 \\
Cellular component organization & 0.0039 \\
Cytoskeleton organization and biogenesis & 0.0039 \\
Photorespiration & 0.0053 \\
Seryl-tRNA aminoacylation & 0.0069 \\
Aspartate family amino acid metabolic process & 0.0071 \\
mRNA metabolic process & 0.011 \\
Response to drug, underrepresented & 0.020 \\
Drug transport, underrepresented & 0.020 \\
Pyrimidine base metabolic process & 0.024 \\
Phosphate transport & 0.024 \\
Inflammatory response & 0.024 \\
Oxidative phosphorylation & 0.0013 \\
ATP synthesis coupled electron transport & 0.0024 \\
Programmed cell death & 0.0028 \\
Cell development & 0.0043 \\
Glycerol metabolic process & 0.0058 \\
Alcohol metabolic process & 0.0058 \\
Hormone metabolic process & 0.0058 \\
Phagocytosis & Endocytosis & 0.0081 \\
Hormone catabolic process & 0.0081 \\
Photomorphogenesis & 0.012 \\
Transcription & 0.014 \\
Aa-like & & 0.017 \\
& & 0.023 \\
& & 0.031 \\
& & 0.034 \\
& & 0.034 \\
\hline
\end{tabular}

phylogenetic trees, interpreted as being an evolutionary dead-end $[64,65]$. Thus, $A a$ homoeologs may contribute more to the fitness of an $F_{1} A s$, as they originate from an outcrossing species. In the future, we will test this hypothesis by population 'allele-specific' resequencing and applying molecular evolution tests to homoeologs separately.

Our second hypothesis involves historical factors. Suppose the southern-adapted $A t$ accession hybridized with the northern-adapted $A a$ accession, and that the emerging $A s$ accession spent most of the 12,000 to 300,000 years in the northern environment $[37,39]$. Aa-originated homoeologs would be a better fit for the environment, would be more frequently retained, and would evolve to be preferentially used [66]. To test this 


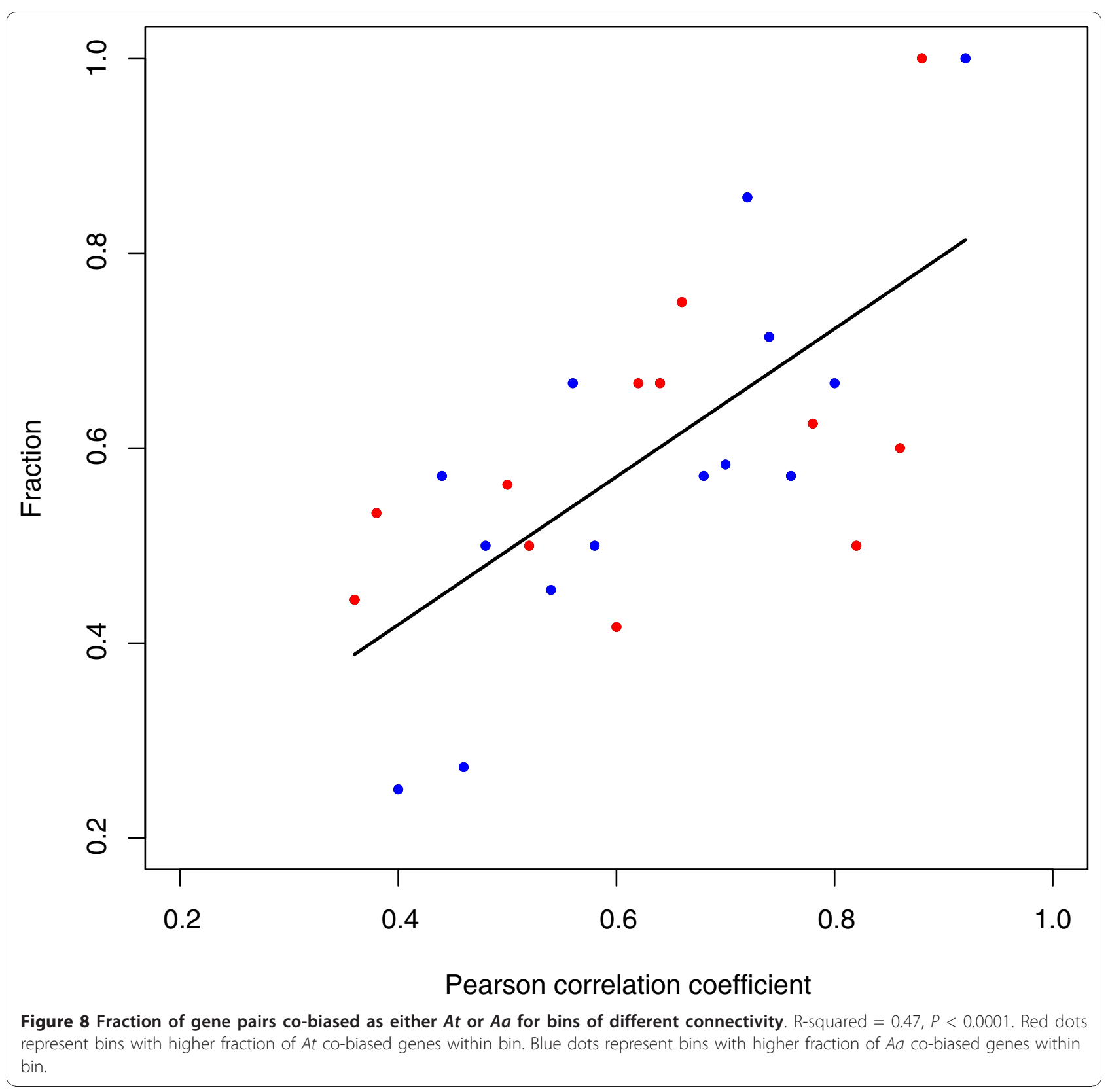

hypothesis, one must sample As accessions from multiple locations, resequence their genomes and transcriptomes and identify environment-specific molecular evolution since the unique As speciation event. Our

Table 5 Co-biased pairs of Arabidopsis suecica homoeologs in Arabidopsis thalianat-identified gene networks

\begin{tabular}{lccc}
\hline Classification & $\begin{array}{c}\text { Co-biased as } \\
\boldsymbol{A t}\end{array}$ & $\begin{array}{c}\text { Biased as } \boldsymbol{A t} \text { and } \\
\boldsymbol{A a}\end{array}$ & $\begin{array}{c}\text { Co-biased as } \\
\boldsymbol{A a}\end{array}$ \\
\hline Occurrence & 219 & 302 & 325 \\
Expected & 173.1 & 419.2 & 253.7 \\
\hline
\end{tabular}

$\chi^{2}$ test, $P<6 \mathrm{e}-08$. model assumes a large standing variation in the genome and transcriptome, which has been well-documented in Tragopogon [35,36]. A more direct, rather than biogeographic-type, evidence might be obtained with Gossypium [14]. This species displays a similar strengthening of parentally skewed expression when natural allotetraploids are compared with $\mathrm{F}_{1}$ allotetraploid controls.

Thirdly, recall that the $A a$ transcription machinery is preferentially expressed in $F_{1} A s$ [53]. Homoeologs preadapted to function under $A a$ transcriptional control will then be selected for, reinforcing this initial pattern. Homoeolog-specific methylation might be at the heart of these processes $[45,46]$. Indirectly supporting this 
idea, $A a$-like genes exhibited enrichment in the 'gene expression' category (with subprocesses: transcription, translation, RNA processing, and gene silencing by miRNA). Recent reports in Arabidopsis and Brassica allopolyploids indicate a high proportion of nonadditive expression for genes within these categories as well $[53,67,68]$. Similar results have also been shown in Senecio $[69,70]$.

\section{Resolving incompatibilities in allotetraploid networks}

Imagine ancestral genes $A 1$ and $A 2$ that formed a functional dimer in the common ancestor of $A a$ and $A t 5$ million years ago. These genes evolved into $A t 1$ and $A t 2$ orthologs in the At lineage, and into $A a 1$ and $A a 2$ orthologs in the $A a$ lineage. Within these lineages, At1 and At 2 have been selected for the ability to form a dimer. Likewise, co-evolution has been taking place between $A a 1$ and $A a 2$ proteins [48]. In $F_{1} A s$, along with the parental dimers At1-At2 and Aa1-Aa2, there will also be heterologous At1-Aa2 and Aa1-At2 dimers. Are these dimers likely to be functional [48]? Dobzhansky and Muller hypothesized that some would not be [71]. Strongly decreased fitness of $A t \times A a \mathrm{~F}_{1}$ and $\mathrm{F}_{2}$ seeds, and meiotic disruptions in $\mathrm{F}_{1}$ 's, attest to the presence of intrinsic incompatibilities contributing to the reproductive isolation of these two species, and some genes involved have been characterized $[61,62]$.

An allotetraploid might walk an evolutionary path to fitness restoration by preferentially co-expressing only one parental set of interacting homoeologs, with mixed networks being less common. The data confirmed our expectation that homoeologous networks in fact evolved towards pure $A a$ or $A t$ profiles. This type of 'D-M homoeolog conflict resolution' should be typical for polyploid ancestors and might potentially contribute to the fractionated genomes we observe today $[9,72]$. As we now know the identity of networks having evolved to a 'pure' parental type, our strong prediction is that the experimenter-induced heterologous state in these networks shall result in detectable reproductive losses.

\section{Conclusions}

When an allotetraploid is formed, the functions of homoeologs are partially redundant, and the genome is set for gene silencing and deletion. Thousands of genes affected by these processes in As were identified with tiling arrays and resequencing. These new computational approaches enable the use of widely available and economical tiling microarrays for the whole-genome analyses of species closely related to the sequenced references. In the As allotetraploid, more $A t$-originated homoeologs are lost and silenced than $A a$-originated homoeologs. We hypothesize that these
$A a$-favoring biases are not random, but rather represent a signature of an evolutionary process. Whenever more than one gene experiences silencing within a network, the homoeolog bias of the first event influences the likewise bias for the subsequent silencing; networks evolve towards their ancestral types. The mosaics of predominantly pure-parental networks in allotetraploids might contribute to phenotypic variability and plasticity, and enable the species to exploit a larger range of environments.

\section{Materials and methods}

\section{Plant material, DNA and RNA extractions}

Affymetrix GeneChip ${ }^{\circledR}$ Arabidopsis Tiling 1.0R Arrays were hybridized with samples from four different sources. Genomic DNA was obtained from tetraploid $A t$ accession Ler [73], tetraploid $A a$ accession Care-1 [58], allotetraploid $A s$ accession Sue-1 [73], and an $F_{1} A s$ produced by crossing the tetraploids $A t$ and $A a$ as maternal and paternal parents, respectively [58]. cDNA was prepared from As leaf samples. All genomic DNA and cDNA samples were hybridized in three biological replicates using standard protocols.

\section{Sample Illumina library preparation}

RNA purification, cDNA synthesis and Illumina library construction was performed using the protocols of Mortazavi et al. [74] with the following modifications. Total RNA, mRNA, and DNA were quantified using a Qubit fluorometer (Invitrogen, Carlsbad, CA, USA). mRNA fragmentation was performed using Fragmentation Reagent (Ambion, Austin, TX, USA) and subsequently cleaned through an RNA cleanup kit (Zymo Research, Irvine, CA, USA). Additional DNA and gel purification steps were conducted using Clean and Concentrator kits (Zymo Research). Illumina sequences are available for download at the NCBI Short Read Archive under the accession SRA025958.

\section{Microarray preprocessing and normalization}

The Arabidopsis Tiling Microarray is composed of over 3.2 million probe pairs tiled throughout the complete $A t$ genome. Probes are tiled at an average of 35 base pairs. Affymetrix CEL files are available for download from the public repository ArrayExpress under the accessions E-MEXP-2968 and E-MEXP-2969. To ensure that arrays within genotypes are comparable to each other, Robust Multiarray Analysis $[75,76]$ was implemented to perform background correction. Intensities for three biological replicates were summarized with quantile normalization [77]. In addition, intensities for the three biological replicates of $A s$ and $F_{1} A s$ were summarized altogether with quantile normalization. Consistency and density 
plots may be found in the Additional files. PM probes exhibited some mismatches for the At genotype, as this array is based on a different reference; the arrays exhibited an additional lower hybridization intensity peak. PM probes from conserved exon regions were much more robust.

As expected from interspecific sequence divergence, the number of $A a$ higher intensity probes decreased, while the number of lower intensity probes increased. Note, however, that 'conservative features' and 'divergent features' peak at similar intensities in both species, making the analyses easier. Similar to $A t, A a$ lower intensity probes were overrepresented in non-coding regions.

\section{Identifying As genomic regions with putative multi-gene alterations}

Probe intensities among three biological replicates in $A s$ were averaged and paired with the corresponding average among the three $F_{1} A s$ replicates. For each gene, a paired Wilcoxon rank-sum test (FDR <0.05) [78] of all probes was used to identify genes with differential hybridization. The significance of individual genes might be misleading, but the pattern for multigene regions is robust. We scanned for windows in which at least $27(90 \%)$ out of 30 genes exhibited unidirectional stronger or unidirectional weaker hybridization in $A s$ in comparison with $F_{1} A s$. We also required these differences to be significant at FDR $<0.05$ for at least 9 (30\%) genes. Overlapping windows were collapsed to identify the entirety of these regions.

\section{Multi-genotype array normalization and identification of diagnostic features}

Our goal here is to select probe features enabling the comparison of $A t$ and $A a$ signal representation in $A s$ DNA and RNA. To enable cross-comparison of DNA and RNA, the analyses have to be made gene-by-gene, with DNA and RNA hybridization signals normalized to the same level with each gene.

First, probes representing conserved signatures between genotypes were identified and used to scale the entire gene. For every probe in a gene, its average intensity among replicates in $A t$ was compared to the average intensity in $A a$. These ratios formed a unimodal distribution and the peak of this distribution was used as the scaling factor for which to normalize between genotypes for that gene. Mathematically, for probe $i$ in the gene, the average intensity among $j$ biological replicates in both genotypes is defined as:

$$
A_{i}=\frac{1}{3} \sum_{j=1}^{3} a_{i j} \text { and } T_{i}=\frac{1}{3} \sum_{j=1}^{3} t_{i j}
$$

where $a_{i j}$ and $t_{i j}$ represent the probe intensities of the $j$ th replicate of the $i$ th probe in $A a$ and $A t$, respectively. Defining $X_{i}$ as:

$$
X_{i}=\frac{T_{i}}{A_{i}} \sim f(x)
$$

The scaling factor, $x_{\max }$ is defined as:

$$
x_{\max }=\underset{x}{\arg \max } f(x)
$$

The value for $x_{\max }$ was estimated using the mlv function in R, which calculates the kernel density and searches for $x$ that maximizes that estimated density function. From hereon, we replace all $a_{i j}$ values with rescaled values represented by $\operatorname{product}\left(x_{\max }, a_{i j}\right)$. We disregarded genes whose $f(x)$ failed the Shapiro-Wilks normality test. This normalization method is similar to one recently outlined by Robinson and Oshlack [79], where a scaling parameter is used to normalize between two samples.

Second, we identified single feature polymorphisms or DFs between $A t$ and $A a$ using a Welch $t$-test of $\log 2-$ transformed values, followed by controlling FDR to be smaller than 0.05 . These approaches enabled us to analyze homoeolog-specific retention in 24,344 out of approximately 39,000 At genes.

\section{Analysis of DFs in DNA samples from As}

If an $A s$ gene retained both parental homoeologs, we should observe an equal mix of $A t$ and $A a$ signals. A linear model was used to determine whether $A s$ has probe intensities within a gene contributed by i) both parents (mixed), ii) parental $A t$ only (At-like), or iii) parental $A a$ only ( $A a$-like). For a gene with $\mathrm{n} \mathrm{DFs}$, the vector of intensities, $S=\left[S_{1}, S_{2}, \ldots, S_{n}\right]$, may be contributed by corresponding $A a$ - and $A t$-specific signals, such that $\mathrm{S}=\alpha 1 \cdot \mathrm{A}+\beta 1 \cdot \mathrm{T}$ and the contribution of $A a, \alpha 1$, can be estimated using a simple linear regression. Specifically:

$$
S_{i j}=\alpha_{1} A_{i}+\beta_{1} T_{i}+\varepsilon_{i j}
$$

where $i=1,2, . ., \mathrm{n}, j=1,2,3$ for the three biological replicates, and $A_{i}$ and $T_{i}$ are the mean intensities in $A a$ and $A t$, respectively. $\varepsilon_{i j}$ are error terms that are independent random variables from a normal distribution with a mean 0 and variance $\sigma^{2}$. The strength of our experimental design is in $F_{1} A s$, in which a null model holds true for genomic DNA. For $F_{1} A s$, this expectation is:

$$
F_{i j}=\alpha_{2} A_{i}+\beta_{2} T_{i}+\varepsilon_{i j}
$$


To detect deviations from the null, we tested whether $\alpha 1$ is significantly different from $\alpha 2$. Under the null hypothesis that $\alpha 1=\alpha 2$, and assuming $\alpha+\beta=1$ :

$$
X=\frac{\frac{1}{2}\left(\hat{\alpha}_{1}-\hat{\alpha}_{2}\right)^{2} \sum_{i=1}^{3 n}\left(A_{i}-T_{i}\right)^{2}}{\left[\frac{\sum_{i=1}^{3 n}\left(\left(S_{i}-T_{i}-\hat{\alpha}_{1}\left(A_{i}-T_{i}\right)\right)^{2}+\left(F_{i}-T_{i}-\hat{\alpha}_{2}\left(A_{i}-T_{i}\right)\right)^{2}\right]}{6 n-1}\right]}
$$

follows an $\mathrm{F}$ distribution with 1 and $6 \mathrm{n}-1$ degrees of freedom. This assumption of $\alpha+\beta=1$ can be made since the contributions of $A a$ and $A t$ are weighted. The bias was labeled as $A a$-like if $\alpha 1>\alpha 2$ and as $A t$-like if $\alpha 1$ $<\alpha 2$. To account for multiple testing issues arising from thousands of genes tested, Benjamini-Hochberg's FDR was employed to adjust the significance level at 0.05 [78].

As with all linear regression models, we assume that the error terms follow a normal distribution. We investigated this by applying a Shapiro-Wilks test on each gene to ensure that they were normal. We removed over 7,000 genes that failed these tests. We found little discrepancy for the results of the analyses when $\alpha 1$ was defined as the At contribution. We also determined significance by performing a permutation test for each gene and found little discrepancy with the F distribution shown above.

\section{Analysis of DFs in As transcripts}

Since we are estimating the relative contribution of $A a$ rather than the absolute, the expression level of every gene in the As transcriptome was normalized to identical hybridization levels with its corresponding genomic DNA. This was done using probes representing conserved signatures, identified as previously described. We then analyzed the homoeolog-specific expression with the same linear model approach as above, using DFs identified between RNA and DNA, and $\alpha$ found in $A s$ DNA as the null reference point. When these intensities of DFs are biased in one direction, we can determine homoeolog-specific expression. Furthermore, for each gene, $\alpha$ was estimated by regressing over all DFs in the set, minimizing spurious effects of individual probes. Forty-nine percent of genes were expressed. Distributions of intensities for conserved features in As DNA and RNA prior to and after gene-wise normalization are shown in the Additional files. The homoeolog-specific expression was assayed in 18,876 genes.

\section{Illumina data analysis}

Pair-ended 72-base Illumina reads were aligned and mapped allowing up to 10 mismatches using bwa [80] to $102 A a$ transcript sequences and their orthologous $A t$ sequences. A pairwise global alignment identified SNPs and short insertion/deletion variants between orthologous $A a$ and $A t$ gene pairs. Reads that mapped to either of the two orthologs were scanned for these variants to ensure that they were clustered with the appropriate ortholog (Figure 6). The number of reads mapped to each ortholog was normalized to FPK (fragments per kilobase of exon) to account for slightly variable sequence length between orthologs. This analysis and its results are summarized in Figures 6 and 7, and in Additional file 5.

\section{Divergence of homeolog sequences vs expression}

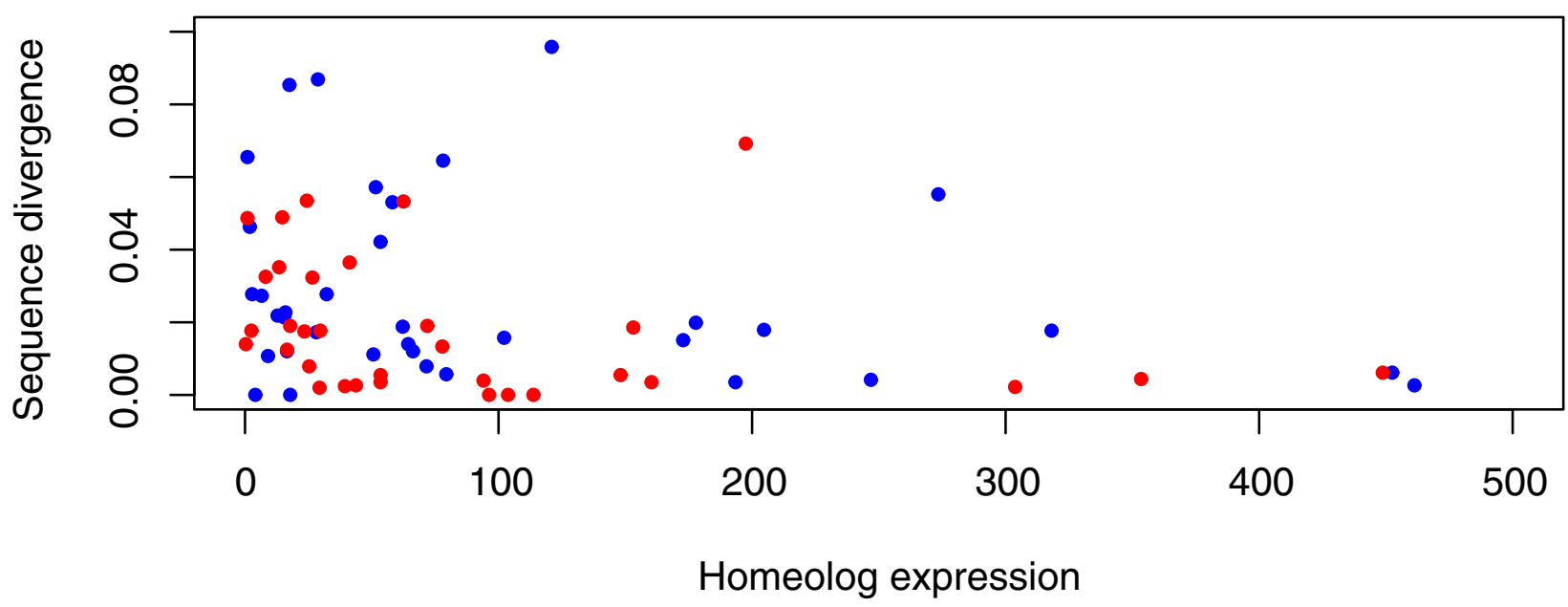

Figure 9 Divergence of $A t$ and $A a$ homoeologs in $A s$ in comparison with At and Aa references (Y-axis) compared to homoeologspecific expression (X-axis) 


\section{Variation within $A a$ and $A t$}

Note that although extant accessions of $A a, A t$, and $F_{1} A s$ were used, As was formed 12 to $300 \mathrm{KYA}$, perhaps from different accessions. DFs and Illumina resequencing may potentially result in misleading conclusions. Nevertheless, 5 million years of sequence divergence between $A a$ and At compares favorably with the smaller amount of standing sequence variation and with the unaccounted extra divergence since $A s$ formation. From the above resequencing data, we estimated the divergence of the $A a$ homoeolog within $A s$ from the homologous gene in $A a$. Likewise, we estimated the divergence of the $A t$ homoeo$\log$ within As from the homologous gene in At. Consistent with high sequence variation in $A a$ [43], the divergence from parental homologs is larger in $A a$, as sequence variation in natural $A t$ is very limited [42]. This would result in fewer $A a$-like calls, and lower biases detected in this manuscript. Note that, as expected from [66], stronger expressed genes appear more conserved and exhibit lesser $A a$ and $A t$ divergences (Figure 9).

\section{Additional material}

\section{Additional file 1: Differential hybridization between $A s$ and $F_{1} A s$}

Excel table showing 6,790 genes with differential hybridization between As and $F_{1}$ As (Wilcoxon ranked sum test, FDR <0.05).

Additional file 2: Differentially hybridized clusters between As and $\boldsymbol{F}_{\boldsymbol{1}} \boldsymbol{A s}$. Excel table showing 1,643 genes found within differentially hybridized clusters between $A s$ and $F_{7} A s$. Clusters contain at least 30 genes with a strong unidirectional bias, where at least 27 genes have the same bias, and significant for at least 9 genes.

Additional file 3: Outline of genes included and analyzed. Excel table outlining the number of genes discarded and included at each step in the analysis.

Additional file 4: Homoeolog-specific retention in As DNA. Excel table showing 938 genes with homoeolog-specific retention in As DNA.

Additional file 5: Comparison of homoeolog-specific expression estimated from At tiling microarray and Illumina resequencing. Excel table showing comparison of expression for 102 genes using both At tiling microarrays and Illumina resequencing.

Additional file 6: Summary of probe hybridization intensities between $A t, A a, A s$, and $F_{1} A s$. Probe hybridization intensities are shown for various regions throughout the genome (Figures S1 to S12). Density plots are shown for probe hybridization of DNA for PM and MM probes (Figures S13 to S16). A density plot is shown for conserved probes in As DNA and As RNA before and after gene-level normalization.

\section{Abbreviations}

Aa: Arabidopsis arenosa; AFLP: amplified fragment length polymorphism; As: Arabidopsis suecica; At: Arabidopsis thaliana; DF: diagnostic feature; $F_{1} A s: F_{1}$ artificial allotetraploid; FDR: false discovery rate; KYA: thousand years ago; SNP: single-nucleotide polymorphism.

\section{Acknowledgements}

BPD and LC were supported by grant DBI0733857 from NSF Plant Genome Research Program. The authors are grateful to Joseph Fass, Meric Lieberman and Victor Missirian at the UC Genome Center for providing of A. arenosa sequences. The authors would also like to thank the anonymous reviewers for their comments and suggestions during the review of the manuscript.

\section{Author details}

${ }^{1}$ Molecular and Computational Biology, University of Southern California, 1050 Childs Way, RRI 201, Los Angeles, CA 90089-2910, USA. Genome Center and Department of Plant Biology, University of California at Davis, 451 Health Services Drive, Davis, CA 95616, USA. ${ }^{3}$ Current address: Department of Horticulture and Landscape Architecture, Purdue University, 625 Agriculture Mall Drive, West Lafayette, IN 47907-2010, USA. ${ }^{4}$ School of Plant Sciences, University of Arizona, 1140 E. South Campus Drive, Forbes Building, Room 303, Tucson, AZ 85721-0036, USA.

\section{Authors' contributions}

PLC performed the computational and statistical analysis of the data, carried out the molecular resequencing, and drafted the manuscript. BPD performed sequence extraction and microarray experiments, and drafted the manuscript. MM performed sequence extraction and microarray experiments. LC participated in the design of the study. SVN conceived the study, participated in its design and coordination, and drafted the manuscript. All authors read and approved the final manuscript.

\section{Competing interests}

The authors declare that they have no competing interests.

Received: 31 July 2010 Revised: 6 November 2010

Accepted: 23 December 2010 Published: 23 December 2010

\section{References}

1. Ehrendorfer F: Polyploidy and distribution. Basic Life Sci 1979, 13:45-60.

2. Grant V: Plant Speciation. New York, USA: Columbia University; 1981.

3. Osborn TC, Pires JC, Birchler JA, Auger DL, Chen ZJ, Lee HS, Comai L, Madlung A, Doerge RW, Colot V, Martienssen RA: Understanding mechanisms of novel gene expression in polyploids. Trends Genet 2003, 19:141-147.

4. Masterson J: Stomatal size in fossil plants: evidence for polyploidy in majority of angiosperms. Science 1994, 264:421-424.

5. Wood TE, Takebayashi N, Barker MS, Mayrose I, Greenspoon PB, Rieseberg $\mathrm{LH}$ : The frequency of polyploid speciation in vascular plants. Proc Natl Acad Sci USA 2009, 106:13875-13879.

6. Otto SP, Whitton J: Polyploid incidence and evolution. Annu Rev Genet 2000, 34:401-437.

7. Nuzhdin SV, Wayne ML, Harmon KL, Mclntyre LM: Common pattern of evolution of gene expression level and protein sequence in Drosophila. Mol Biol Evol 2004, 21:1308-1317.

8. Ranz JM, Castillo-Davis Cl, Meiklejohn CD, Hartl DL: Sex-dependent gene expression and evolution of the Drosophila transcriptome. Science 2003, 300:1742-1745.

9. Soltis PS, Soltis DE: The role of hybridization in plant speciation. Annu Rev Plant Biol 2009, 60:561-588.

10. Adams KL, Percifield R, Wendel JF: Organ-specific silencing of duplicated genes in a newly synthesized cotton allotetraploid. Genetics 2004, 168:2217-2226.

11. Adams KL, Wendel JF: Novel patterns of gene expression in polyploid plants. Trends Genet 2005, 21:539-543.

12. Chen ZJ, Ni Z: Mechanisms of genomic rearrangements and gene expression changes in plant polyploids. Bioessays 2006, 28:240-252.

13. Feldman M, Liu B, Segal G, Abbo S, Levy AA, Vega JM: Rapid elimination of low-copy DNA sequences in polyploid wheat: a possible mechanism for differentiation of homoeologous chromosomes. Genetics 1997, 147:1381-1387.

14. Flagel L, Udall JA, Nettleton D, Wendel JF: Duplicate gene expression in allopolyploid Gossypium reveals two temporally distinct phases of expression evolution. BMC Biol 2008, 6:16.

15. Kashkush K, Feldman M, Levy AA: Gene loss, silencing and activation in a newly synthesized wheat allotetraploid. Genetics 2002, 160:1651-1659.

16. Lee HS, Chen ZJ: Protein-coding genes are epigenetically regulated in Arabidopsis polyploids. Proc Natl Acad Sci USA 2001, 98:6753-6758.

17. Liu B, Brubaker CL, Mergeai G, Cronn RC, Wendel JF: Polyploid formation in cotton is not accompanied by rapid genomic changes. Genome 2001, 44:321-330.

18. Liu B, Vega JM, Feldman M: Rapid genomic changes in newly synthesized amphiploids of Triticum and Aegilops. II. Changes in low-copy coding DNA sequences. Genome 1998, 41:535-542. 
19. Madlung A, Masuelli RW, Watson B, Reynolds SH, Davison J, Comai L: Remodeling of DNA methylation and phenotypic and transcriptional changes in synthetic Arabidopsis allotetraploids. Plant Physiol 2002, 129:733-746.

20. Matzke MA, Scheid OM, Matzke AJM: Rapid structural and epigenetic changes in polyploid and aneuploid genomes. Bioessays 1999, 21:761-767.

21. Otto SP: The evolutionary consequences of polyploidy. Cell 2007, 131:452-462.

22. Pontes $\mathrm{O}, \mathrm{Ng}$ P, Silva M, Lewis MS, Madlung A, Comai L, Viegas W, Pikaard CS: Chromosomal locus rearrangements are a rapid response to formation of the allotetraploid Arabidopsis suecica genome. Proc Natl Acad Sci USA 2004, 101:18240-18245.

23. Song K, Lu P, Tang K, Oshlack A: Rapid genome change in synthetic polyploids of Brassica and its implications for polyploid evolution. Proc Natl Acad Sci USA 1995, 92:7719-7723.

24. Wang J, Tian L, Madlung A, Lee HS, Chen M, Lee JJ, Watson B, Kagochi T, Comai $L$, Chen ZJ: Stochastic and epigenetic changes of gene expression in Arabidopsis polyploids. Genetics 2004, 167:1961-1973.

25. Wendel JF: Genome evolution in polyploids. Plant Mol Biol 2000, 42:225-249.

26. Adams KL, Wendel JF: Polyploidy and genome evolution in plants. Curr Opin Plant Biol 2005, 8:135-141.

27. Adams KL, Cronn RC, Percifield R, Wendel JF: Genes duplicated by polyploidy show unequal contributions to the transcriptome and organspecific reciprocal silencing. Proc Natl Acad Sci USA 2003, 100:4649-4654.

28. Bottley A, Koebner RM: Variation for homoeologous gene silencing in hexaploid wheat. Plant J 2008, 56:297-302.

29. Bottley A, Xia GM, Koebner RM: Homoeologous gene silencing in hexaploid wheat. Plant J 2006, 47:897-906.

30. Chaudhary B, Flagel L, Stupar RM, Udall JA, Verma N, Springer NM, Wendel JF: Reciprocal silencing, transcriptional bias and functional divergence of homeologs in polyploid cotton (gossypium). Genetics 2009, 182:503-517.

31. Flagel LE, Wendel JF: Evolutionary rate variation, genomic dominance and duplicate gene expression evolution during allotetraploid cotton speciation. New Phytol 2009, 186:184-193.

32. Rapp RA, Udall JA, Wendel JF: Genomic expression dominance in allopolyploids. BMC Biol 2009, 7:18.

33. Buggs RJ, Chamala S, Wu W, Gao L, May GD, Schnable PS, Soltis DE, Soltis PS, Barbazuk WB: Characterization of duplicate gene evolution in the recent natural allopolyploid Tragopogon miscellus by nextgeneration sequencing and Sequenom iPLEX MassARRAY genotyping. Mol Ecol 2010, 19(Suppl 1):132-146.

34. Buggs RJ, Doust AN, Tate JA, Koh J, Soltis K, Feltus FA, Paterson AH, Soltis PS, Soltis DE: Gene loss and silencing in Tragopogon miscellus (Asteraceae): comparison of natural and synthetic allotetraploids. Heredity 2009, 103:73-81.

35. Lim KY, Soltis DE, Soltis PS, Tate J, Matyasek R, Srubarova H, Kovarik A, Pires JC, Xiong Z, Leitch AR: Rapid chromosome evolution in recently formed polyploids in Tragopogon (Asteraceae). PLoS One 2008, 3:e3353.

36. Tate JA, Joshi P, Soltis KA, Soltis PS, Soltis DE: On the road to diploidization? Homoeolog loss in independently formed populations of the allopolyploid Tragopogon miscellus (Asteraceae). BMC Plant Biol 2009, 9:80.

37. Säll T, Lind-Halldén C, Jakobsson M, Halldén C: Mode of reproduction in Arabidopsis suecica. Hereditas 2005, 141:313-317.

38. Hulten E: Atlas of the Distribution of Vascular Plants in Northwestern Europe. Stockholm: Generalstabens Litografiska Anstalts Forlag; 1971.

39. Jakobsson M, Hagenblad J, Tavaré S, Säll T, Halldén C, Lind-Halldén C, Nordborg M: A unique recent origin of the allotetraploid species Arabidopsis suecica: evidence from nuclear DNA markers. Mol Biol Evol 2006, 23:1217-1231.

40. Mummenhoff K, Hurka H: Allopolyploid origin of Arabidopsis suecica (Fries) Norrlin: Evidence from chloroplast and nuclear genome markers. Botanica Acta 1995, 108:449-456.

41. Säll T, Jakobsson M, Lind-Halldén C, Halldén C: Chloroplast DNA indicates a single origin of the allotetraploid Arabidopsis suecica. J Evol Biol 2003, 16:1019-1029.

42. Al-Shehbaz IA, O'Kane SL: Taxonomy and phylogeny of Arabidopsis (Brassicaceae). The Arabidopsis Book 2002, 6:1-22.
43. Koch MA, Matschinger M: Evolution and genetic differentiation among relatives of Arabidopsis thaliana. Proc Natl Acad Sci USA 2007, 104:6272-6277.

44. Koch MA, Haubold B, Mitchell-Olds T: Comparative evolutionary analysis of chalcone synthase and alcohol dehydrogenase loci in Arabidopsis, Arabis, and related genera (Brassicaceae). Mol Biol Evol 2000, 17:1483-1498.

45. Chen M, Ha M, Lackey E, Wang J, Chen ZJ: RNAi of met1 reduces DNA methylation and induces genome-specific changes in gene expression and centromeric small RNA accumulation in Arabidopsis allopolyploids. Genetics 2008, 178:1845-1858.

46. Ha M, Lu J, Tian L, Ramachandran V, Kasschau KD, Chapman EJ, Carrington JC, Chen X, Wang XJ, Chen ZJ: Small RNAs serve as a genetic buffer against genomic shock in Arabidopsis interspecific hybrids and allopolyploids. Proc Natl Acad Sci USA 2009, 106:17835-17840.

47. Keightley PD, Otto SP: Interference among deleterious mutations favours sex and recombination in finite populations. Nature 2006, 443:89-92.

48. Coyne JA, Orr HA: The evolutionary genetics of speciation. Philos Trans $R$ Soc Lond B Biol Sci 1998, 353:287-305.

49. Graze RM, McIntyre LM, Main BJ, Wayne ML, Nuzhdin SV: Regulatory divergence in Drosophila melanogaster and $D$. simulans, a genomewide analysis of allele-specific expression. Genetics 2009, 183:547-561, 541SI521SI.

50. Borevitz JO, Hazen SP, Michael TP, Morris GP, Baxter IR, Hu TT, Chen H, Werner JD, Nordborg M, Salt DE: Genome-wide patterns of single-feature polymorphism in Arabidopsis thaliana. Proc Natl Acad Sci USA 2007, 104:12057-12062.

51. Baross A, Delaney AD, Li HI, Nayar T, Flibotte S, Qian H, Chan SY, Asano J, Ally A, Cao M, Birch P, Brown-John M, Fernandes N, Go A, Kennedy G, Langlois S, Eydoux P, Friedman JM, Marra MA: Assessment of algorithms for high throughput detection of genomic copy number variation in oligonucleotide microarray data. BMC Bioinformatics 2007, 8:368.

52. Langmead B, Trapnell C, Pop M, Salzberg SL: Ultrafast and memoryefficient alignment of short DNA sequences to the human genome. Genome Biol 2009, 10:R25.

53. Wang J, Tian L, Lee HS, Wei NE, Jiang H, Watson B, Madlung A, Osborn TC, Doerge RW, Comai L, Chen ZJ: Genomewide nonadditive gene regulation in Arabidopsis allotetraploids. Genetics 2006, 172:507-517.

54. Mezey JG, Nuzhdin SV, Ye F, Jones CD: Coordinated evolution of coexpressed gene clusters in the Drosophila transcriptome. BMC Evol Biol 2008, 8:2.

55. Ma S, Gong Q, Bohnert HJ: An Arabidopsis gene network based on the graphical Gaussian model. Genome Res 2007, 17:1614-1625.

56. Beaulieu J, Jean M, Belzile F: The allotetraploid Arabidopsis thalianaArabidopsis lyrata subsp. petraea as an alternative model system for the study of polyploidy in plants. Mol Genet Genomics 2009, 281:421-435.

57. Chen ZJ, Comai L, Pikaard CS: Gene dosage and stochastic effects determine the severity and direction of uniparental ribosomal RNA gene silencing (nucleolar dominance) in Arabidopsis allopolyploids. Proc Natl Acad Sci USA 1998, 95:14891-14896.

58. Comai L, Tyagi AP, Winter K, Holmes-Davis R, Reynolds SH, Stevens $Y$, Byers B: Phenotypic instability and rapid gene silencing in newly formed Arabidopsis allotetraploids. Plant Cell 2000, 12:1551-1568.

59. Nasrallah ME, Yogeeswaran K, Snyder S, Nasrallah JB: Arabidopsis species hybrids in the study of species differences and evolution of amphiploidy in plants. Plant Physiol 2000, 124:1605-1614.

60. Gillespie JH: Junk ain't what junk does: neutral alleles in a selected context. Gene 1997, 205:291-299.

61. Wright SI, Lauga B, Charlesworth D: Rates and patterns of molecular evolution in inbred and outbred Arabidopsis. Mol Biol Evol 2002, 19:1407-1420.

62. Birchler JA, Veitia RA: The gene balance hypothesis: implications for gene regulation, quantitative traits and evolution. New Phytol 2009, 186:54-62.

63. Heller R, Smith JM: Does Muller's ratchet work with selfing? Genet Res 2009, 32:289-293.

64. Takebayashi N, Morrell PL: Is self-fertilization an evolutionary dead end? Revisiting an old hypothesis with genetic theories and a macroevolutionary approach. Am J Bot 2001, 88:1143-1150.

65. Stebbins GL: Self fertilization and population variability in the higher plants. Am Nat 1957, 91:337-354. 
66. Lynch M, Force A: The probability of duplicate gene preservation by subfunctionalization. Genetics 2000, 154:459-473.

67. Gaeta RT, Yoo SY, Pires JC, Doerge RW, Chen ZJ, Oshlack A: Analysis of gene expression in resynthesized Brassica napus allopolyploids using Arabidopsis 70 mer oligo microarrays. PLoS One 2009, 4:e4760.

68. Ha M, Kim ED, Chen ZJ: Duplicate genes increase expression diversity in closely related species and allopolyploids. Proc Natl Acad Sci USA 2009, 106:2295-2300.

69. Hegarty MJ, Barker GL, Wilson ID, Abbott RJ, Edwards KJ, Hiscock SJ: Transcriptome shock after interspecific hybridization in Senecio is ameliorated by genome duplication. Curr Biol 2006, 16:1652-1659.

70. Hegarty MJ, Jones JM, Wilson ID, Barker GL, Coghill JA, Sanchez-Baracaldo P, Liu G, Buggs RJA, Abbott RJ, Edwards KJ: Development of anonymous cDNA microarrays to study changes to the Senecio floral transcriptome during hybrid speciation. Mol Ecol 2005, 14:2493-2510.

71. True JR, Haag ES: Developmental system drift and flexibility in evolutionary trajectories. Evol Dev 2001, 3:109-119.

72. Thomas BC, Pedersen B, Freeling M: Following tetraploidy in an Arabidopsis ancestor, genes were removed preferentially from one homeolog leaving clusters enriched in dose-sensitive genes. Genome Res 2006, 16:934-946.

73. Dilkes BP, Spielman M, Weizbauer R, Watson B, Burkart-Waco D, Scott RJ, Comai L: The maternally expressed WRKY transcription factor TTG2 controls lethality in interploidy crosses of Arabidopsis. PLoS Biol 2008, 6 : e308.

74. Mortazavi A, Williams BA, McCue K, Schaeffer L, Wold B: Mapping and quantifying mammalian transcriptomes by RNA-Seq. Nat Methods 2008, 5:621-628.

75. Irizarry RA, Bolstad BM, Collin F, Cope LM, Hobbs B, Speed TP: Summaries of Affymetrix GeneChip probe level data. Nucleic Acids Res 2003, 31:e15.

76. Irizarry RA, Hobbs B, Collin F, Beazer-Barclay YD, Antonellis KJ, Scherf U, Speed TP: Exploration, normalization, and summaries of high density oligonucleotide array probe level data. Biostatistics 2003, 4:249-264.

77. Bolstad BM, Irizarry RA, Astrand M, Speed TP: A comparison of normalization methods for high density oligonucleotide array data based on variance and bias. Bioinformatics 2003, 19:185-193.

78. Benjamini $Y$, Hochberg $Y$ : Controlling the false discovery rate: a practical and powerful approach to multiple testing. J R Statist Soc B 1995, 57:289-300[http://www.jstor.org/pss/2346101].

79. Robinson MD, Oshlack A: A scaling normalization method for differential expression analysis of RNA-seq data. Genome Biol 2010, 11:R25.

80. Li H, Durbin R: Fast and accurate short read alignment with Burrows Wheeler transform. Bioinformatics 2009, 25:1754-1760.

\section{doi:10.1186/gb-2010-11-12-r125}

Cite this article as: Chang et al:: Homoeolog-specific retention and use in allotetraploid Arabidopsis suecica depends on parent of origin and network partners. Genome Biology 2010 11:R125.

\section{Submit your next manuscript to BioMed Central and take full advantage of:}

- Convenient online submission

- Thorough peer review

- No space constraints or color figure charges

- Immediate publication on acceptance

- Inclusion in PubMed, CAS, Scopus and Google Scholar

- Research which is freely available for redistribution

Submit your manuscript at www.biomedcentral.com/submit
Biomed Central 